Proceedings of the XXIII Conference on Applied Crystallography, Krynica Zdrój, Poland, September 20-24, 2015

\title{
Analysis of Crystallite Size Changes in an Oxide Layer Formed on Steel Used in the Power Industry
}

\begin{abstract}
M. GWOŹDZIK*
Institute of Materials Engineering, Częstochowa University of Technology, Częstochowa, Poland

The paper presents results of studies on the crystallite sizes of oxide layer formed during a long-term operation on steel at an elevated temperature. This value was determined by a method based on analysis of the diffraction line profile, according to a Scherrer formula. The oxide layer was studied on a surface and a cross-section at the inner site on the pipe inlet, at the fire and counter-fire wall of the tube. X-ray studies were carried out on the inner surface of a tube (in a flowing medium environment), then the layer's surface was polished and the diffraction measurements repeated to reveal differences in the originated oxides layer. X-ray phase analysis was performed by the use of a SEIFERT $3003 \mathrm{~T} / \mathrm{T}$ X-ray diffractometer, with a cobalt source of $\lambda_{\mathrm{Co}}=0.17902 \mathrm{~nm}$ wavelength. X-ray diffraction measurements were performed in the $20 \div 120^{\circ}$ range of angles with an angular step of $0.1^{\circ}$. To interpret the results the diffractograms were described by a pseudo Voigt curve using the Analyze software. A computer software and the DHN PDS, PDF4+2009 crystallographic database were used for the phase identification. The results showed that the crystallite sizes have an effect on the properties of the oxide. It has been shown that the outer oxide layer having larger crystallites, is more porous and thus more brittle.
\end{abstract}

DOI: 10.12693/APhysPolA.130.935

PACS/topics: 81.05.Bx, 81.16.Pr, 81.65.Mq

\section{Introduction}

In high temperature and with the presence of oxygen, which is in air, the steels undergo oxidation, mainly the low carbon steel and the low alloy steel. In the initial period of heating, the oxidation pace is higher, however over time it is lower. In the initial period, the iron oxides which are created on energetic devices long term operated in high temperature, both they protect steel from excessive oxidation and the iron oxides act as the heat insulator. Consequently, over time, the thickness of the oxide increases and the temperature should be increased, because the temperature of the medium must be constant. According to the authors [1], each $0.03 \mathrm{~mm}$ in thickness of the oxide layer increases the temperature from 0.6 to $1{ }^{\circ} \mathrm{C}$. The growth of the oxide layer (the result of corrosion) has the influence on the thickness of the pipe, which then causes an increase of stress in the wall.

Generally, the growth of oxide layer is accompanied by the development of cracks and the partial removal of the oxide layer, therefore the protective oxide layer becomes less effective during the next oxidation [2]. According to literature [2], the destruction of oxide layers goes according to two mechanisms, i.e. by cracking (I) and by flaking and the next by chipping (II). The oxide will be cracking, when the volume of the oxide is significantly lower than the material in which the oxide was created. On the other hand, the oxide will be chipping when the volume of the oxide is significantly higher than the material on which the oxide was created. In papers $[3,4]$, it has been shown that the initiation of damages can be created: (1) between the oxide layer and steel, (2) inside

\footnotetext{
*corresponding author; e-mail: gwozdzik@wip.pcz.pl
}

the same oxide layer, (3) between two different oxide layers. In elements which are used in power industry, the chipping oxides can flow with steam, which can cause the obstruction of knee pipes and the sedimentation of chipping oxides in the turbine [1].

An intensive development of technology causes continuous increase of a wide base of research methods such as: atomic force microscopy (AFM) [5, 6], scanning electron microscopy (SEM) $[7,8]$ and X-ray diffraction (XRD) [7-15]. Especially methods such as XRD or SEM are widely used for analysis of the oxide layers $[4,7,11,13-15]$.

The paper contains the results of XRD - crystallite sizes of oxide layers (hematite and magnetite) created on 10CrMo9-10 steel operated for a long time at an elevated temperature.

The size of crystallites was determined by the Scherrer relationship. The Scherrer method is one of methods for oxide crystallites size determination in the literature [1115]. Methods based on the analysis of diffraction line profile are used to determine the size of crystallites smaller than $100 \mathrm{~nm}$ and of lattice deformations. Based on the width and the position of the main coat and substrate reflections, the size of the crystallites was determined using the Scherrer formula

$$
D_{h k l}=\frac{k \lambda}{\beta \cos \Theta},
$$

where $D_{h k l}-$ crystallite size in the direction normal to (hkl) $[\mathrm{nm}], k$ - constant $(\approx 1), \lambda$ - radiation wavelength [nm], $\beta$ - reflection width depending on the crystallite size [rad], $\Theta-$ Bragg angle [rad].

\section{Material and experimental methods}

The material studied comprised specimens of 10CrMo9-10 steel taken from a pipeline operated at the temperature of $525{ }^{\circ} \mathrm{C}$ during $200,000 \mathrm{~h}$. 
The oxide layer was studied on a surface and a crosssection at the inner site on the pipe inlet, at the fire and counter-fire wall of the tube.

The analysis of steel chemical composition was carried out using spark emission spectroscopy on a Spectro spectrometer (Table I).

TABLE I

Chemical composition of examined steel, [mass $\% \times 100]$.

\begin{tabular}{c|c|c|c|c|c|c|c}
\hline \hline Acc. to & $\mathrm{C}$ & $\mathrm{Si}$ & $\mathrm{Mn}$ & $\mathrm{P}$ & $\mathrm{S}$ & $\mathrm{Cr}$ & $\mathrm{Mo}$ \\
\hline analysis & 15 & 29 & 47 & 1.9 & 0.7 & 217 & 99 \\
EN [16] & $8-14$ & $<50$ & $40-80$ & $<2$ & $<1$ & $200-250$ & $90-110$
\end{tabular}

Thorough examinations of the oxide layer carried out on the inner surface of tube wall comprised:

- microscopic examinations of the oxide layer were performed using an Olympus SZ61 and GX41 optical microscope,

- thickness measurements of formed oxide layers,

- chemical composition analysis of deposits/oxides using a JEOL JSM-6610LV SEM working with an Oxford EDS electron microprobe X-ray analyser,

- XRD measurements (studying the phase composition, crystallite sizes); the layer was subject to measurements using a Seifert 3003T/T X-ray diffractometer and the radiation originating from a tube with a cobalt anode $\left(\lambda_{\mathrm{Co}}=0.17902 \mathrm{~nm}\right)$. X-ray studies were performed, comprising measurements in a symmetric Bragg-Brentano geometry (XRD). XRD measurements were performed in the $20 \div$ $120^{\circ}$ range of angles with an angular step of $0.1^{\circ}$. To interpret the results the diffractograms were described by a pseudo Voigt curve using the Analyze software. A computer software and the DHN PDS, PDF4+2009 crystallographic database were used for the phase identification.

\section{Results}

In both cases (fire side and counter-fire side), obtained results of microscopic examinations show that the studied steel has a degraded bainitic structure, in fact it is ferrite structure with a lot of carbide precipitates (Fig. 1). From the counter-fire side, locally, the residue after bainite needles can be visible. In both cases (fire side and counter-fire side), the carbide precipitates occur inside grains. Carbide precipitates are also visible on grain boundaries, forming "chains", mainly from the fire side, which is presented in Fig. 1b. The boundary regions are carbon depleted, it resulted in the lower volume fraction of carbides in these regions. It is more intensive from the fire side.

Microscopic studies performed on the cross-section of the oxides layer have shown that the oxide layer on the counter-fire side is $394 \mu \mathrm{m}$ thick, while on the fire side

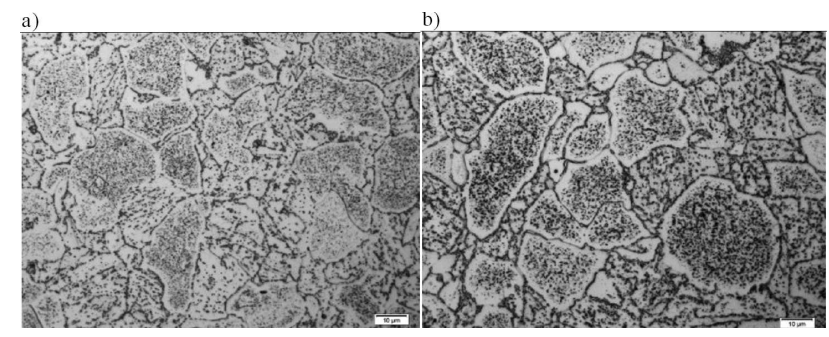

Fig. 1. Microstructure of 10CrMo9-10 steel operated for $200,000 \mathrm{~h}$ at the temperature of $525^{\circ} \mathrm{C}$ : (a) opposite fire wall, (b) fire wall.

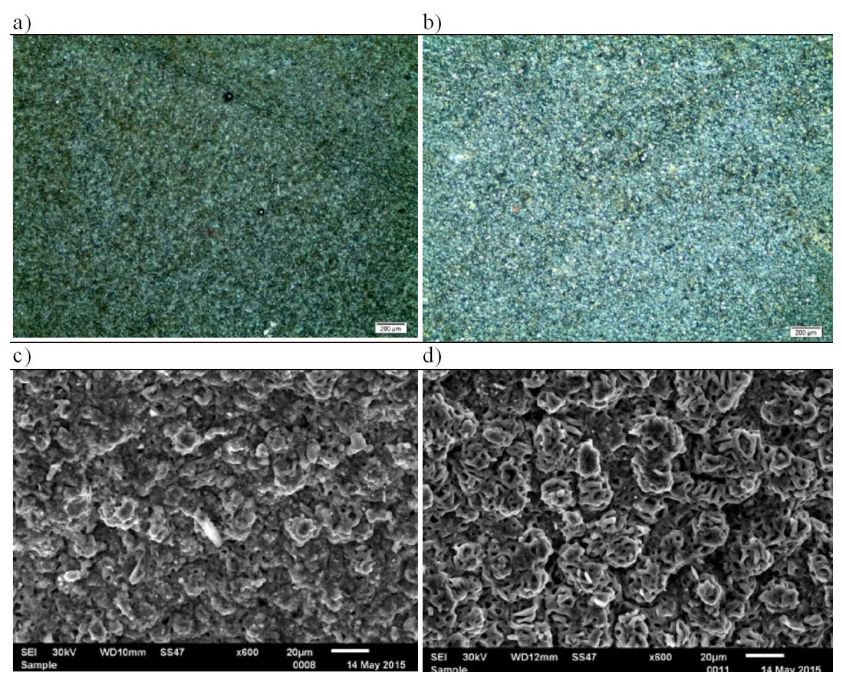

Fig. 2. Oxides formed on 10CrMo9-10 steel operated at $525{ }^{\circ} \mathrm{C}$ during $200,000 \mathrm{~h}$ : (a) opposite fire wall LM, (b) fire wall LM, (c) opposite fire wall SEM, (d) fire wall SEM.

- $495 \mu \mathrm{m}$, which is presented in Fig. 3. Moreover, it is noticeable that on the fire side the oxide layer is more degraded, which is proved by numerous fissures, pores and spalling occurring mainly in the oxide layer on the flowing medium side. On the counter-fire side only much smaller amounts of pores were observed.

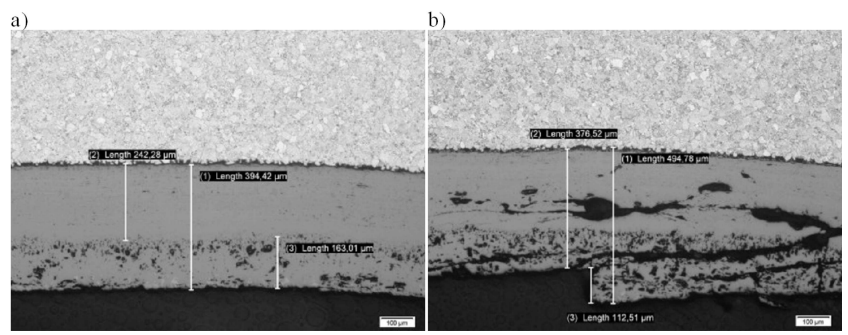

Fig. 3. The thickness of oxides layer formed on the steel examined: (a) opposite fire wall - LM, (b) fire wall - LM.

Performed EDS analysis of chemical composition (Fig. 4) combined with X-ray phase analysis have shown that in both cases the oxide layer is built of hematite $\left(\mathrm{Fe}_{2} \mathrm{O}_{3}\right)$ and magnetite $\left(\mathrm{Fe}_{3} \mathrm{O}_{4}\right)$. In the case of the opposite fire wall apart from $\mathrm{Fe}$ also the others elements 


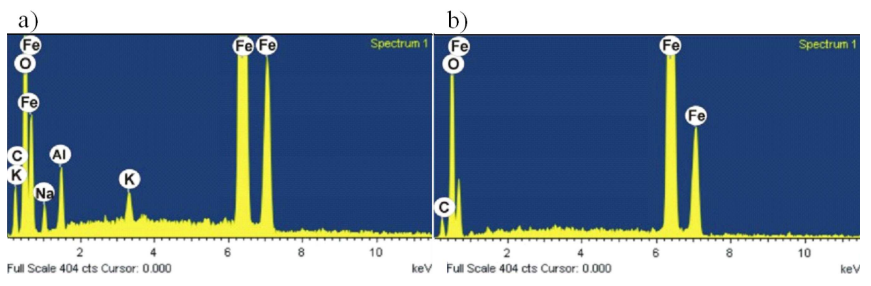

Fig. 4. EDS point microanalysis: (a) opposite fire wall, (b) fire wall.

such as $\mathrm{Al}, \mathrm{Na}$ and $\mathrm{K}$, occur in small amounts. On the fire side, EDS analysis has not shown the presence of the other elements, apart from Fe. The microscopic observations has shown, that on fire side, the deposits layer was totally destroyed.

Three main peaks were marked on diffraction patterns for both oxides. The size of $\mathrm{Fe}_{2} \mathrm{O}_{3}$ crystallites was determined for the (104) plane, while for $\mathrm{Fe}_{3} \mathrm{O}_{4}$ for the (311) plane. Because of close interplanar spacings for $\mathrm{Fe}_{3} \mathrm{O}_{4}$ (311) and $\mathrm{Fe}_{2} \mathrm{O}_{3}$ (110) the peaks were separated using the pseudo Voigt method.

Layers of oxide $394.42 \mu \mathrm{m}$ and $494.76 \mu \mathrm{m}$ thick were studied (Fig. 3), then the surface of the formed layer was polished in 19 and 25 cycles for opposite fire wall and fire wall, respectively. One cycle consisted of polishing the layer to the depth of $25 \mu \mathrm{m}$. During polishing under influence of pressure force, the internal stress are introduced additionally. The internal stress was omitted because the same activity was repeated.

An example of diffraction pattern before and after separating peaks originating from plane (104) and (311) is shown in Fig. 5.

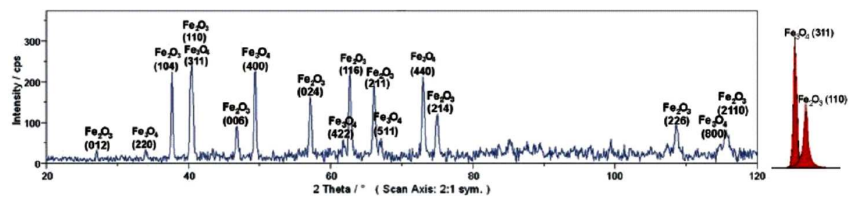

Fig. 5. X-ray diffraction patterns from the oxides layer obtained by means of XRD technique, opposite fire wall.

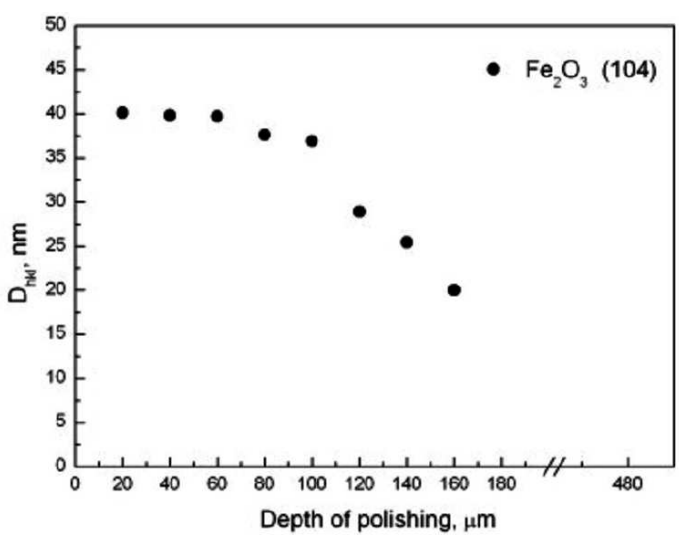

Fig. 6. Determination of crystallite size $D_{h k l}$ for main peaks $\mathrm{Fe}_{2} \mathrm{O}_{3}$, opposite fire wall.

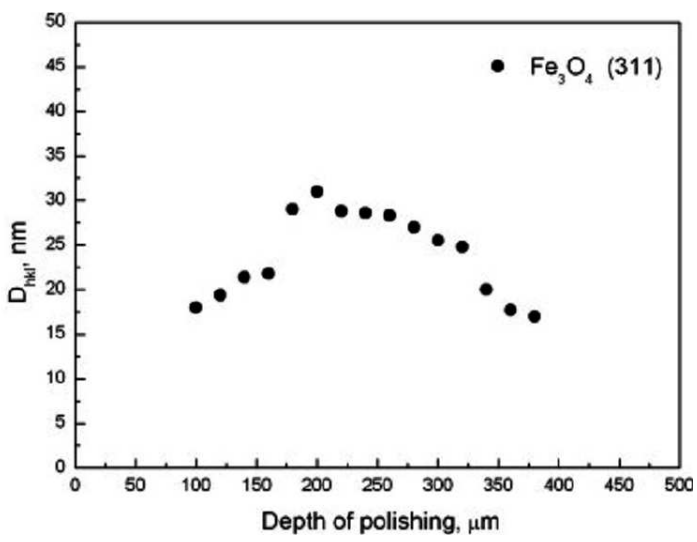

Fig. 7. Determination of crystallite size $D_{h k l}$ for main peaks $\mathrm{Fe}_{3} \mathrm{O}_{4}$, opposite fire wall.

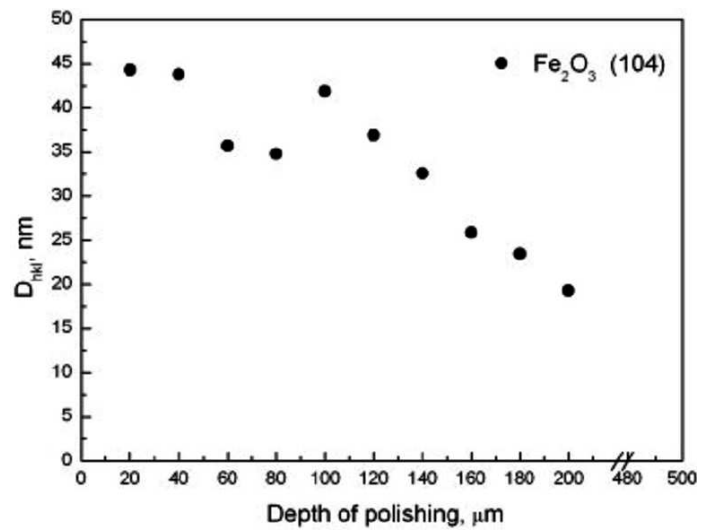

Fig. 8. Determination of crystallite size $D_{h k l}$ for main peaks $\mathrm{Fe}_{2} \mathrm{O}_{3}$, fire wall.

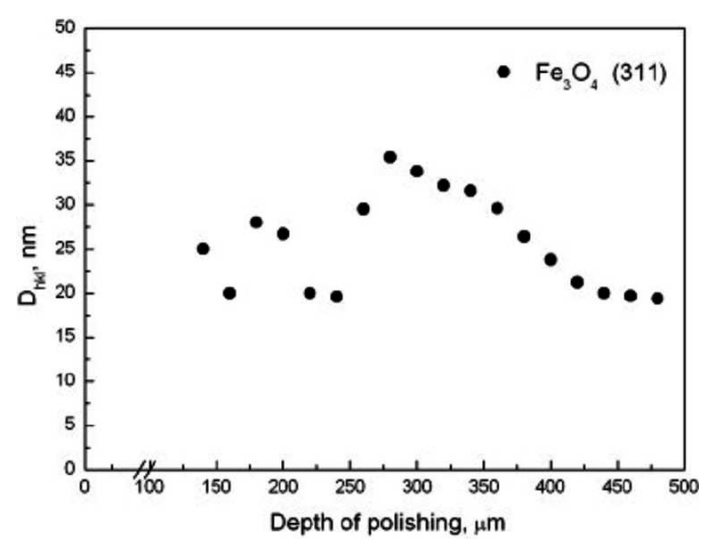

Fig. 9. Determination of crystallite size $D_{h k l}$ for main peaks $\mathrm{Fe}_{3} \mathrm{O}_{4}$, fire wall.

The size of $\mathrm{Fe}_{2} \mathrm{O}_{3} D_{h k l}$ crystallites on the counter-fire side (Fig. 6) after the first three series of polishing is $40 \mathrm{~nm}$, the next series of polishing (4 and 5) has shown as small decrease of crystallite size, and the next three series of polishing have shown that this size is $25-17 \mathrm{~nm}$. After polishing to the depth of $75 \mu \mathrm{m}$ the magnetite crystallite size is $16 \mathrm{~nm}$ (Fig. 7). The next series of polishing 
result in increasing crystallite size, where the maximum of $30 \mathrm{~nm}$ is reached at polishing to the depth of $200 \mu \mathrm{m}$. Further removal of the layer results in diminishing crystallite sizes. In the case of fire side local jumps of crystallite sizes were observed, presented in Figs. 8 and 9. The size of $\mathrm{Fe}_{2} \mathrm{O}_{3}$ and $\mathrm{Fe}_{3} \mathrm{O}_{4}$ crystallites is larger as compared with the counter-fire side (Figs. 6-9). The size of hematite crystallites after polishing 1 and 2 amounts to $45 \mathrm{~nm}$. The next two series of polishing resulted in a fall to $35 \mathrm{~nm}$. After the fifth polishing the size of this oxide crystallites increased to $42 \mathrm{~nm}$. A gradual decrease of crystallite size occurs with the next polishing series (Fig. 8). In the case of magnetite a consecutive removal of layer has shown that the crystallite size after polishing to the depth of $270 \mu \mathrm{m}$ becomes sinusoidal $(25,20,29$, 27, 18, $17 \mathrm{~nm}$ ) (Fig. 9). The next polishing has shown a growth of crystallites size to $35 \mathrm{~nm}$. The subsequent polishing series reveal a downward trend in crystallite sizes.

\section{Summary}

The paper presents results of studies on oxides formed on 10CrMo9-10 steel after a long-term operation. The oxide layer formed on the flowing medium side (inside tube wall) both on the fire and counter-fire side was analyzed. Examinations carried out have shown that the formed layer is thicker and more degraded on the fire side. The size of crystallites determined based on the Scherrer formula on the fire side shows much larger dimensions both for hematite and magnetite. Instead, comparing the size of hematite and magnetite crystallites it is possible to state that in both cases (both for the fire and counter-fire side) $D_{h k l}$ is larger for hematite. The research mainly showed that the outer oxide layer (which occurs directly from flowing medium side) is the most degraded. In this layer there are created many pores and spalling, which shows that the layer is more brittle and porous in comparison with the oxide layer, which occurs directly from steel side, that is more tight. According to the authors [1] the tight oxide layer which is adhering directly to native material (steel), is created by oxidation of metal. On the other hand, the ion which is in flowing factors has influence on creating the porosity oxide layer, which is adhering to the oxide layer.

\section{References}

[1] J. Dobosiewicz, K. Brunné, Energetyka 6-7, 102 (2007).

[2] M.F. Ashby, D.R.H. Jones, Engineering Materials. Properties and Application, WNT, Warszawa 1995 (in Polish)

[3] P.J. Ennis, W.J. Quadakkers, Int. J. Pressure Vessels Piping 84, 75 (2007).

[4] M. Gwoździk, A mechanism of oxide layers degradation on steels long-term operated in the power industry, Monography no. 291, Wydawnictwo Politechniki Częstochowskiej, Częstochowa 2014 (in Polish).

[5] Ş. Ţălu, M. Bramowicz, S. Kulesza, A. Shafiekhani, A. Ghaderi, F. Mashayekhi, S. Solaymani, Ind. Eng. Chem. Res. 33, 8212 (2015).

[6] S. Kulesza, M. Bramowicz, Appl. Surf. Sci. 293, 196 (2014).

[7] M. Gwoździk, Z. Nitkiewicz, Archiv. Civil Mech. Eng. 14, 335 (2014).

[8] K. Labisz, Mat.-wiss. Werkstofftech. 45, 314 (2014).

[9] M. Szafarska, J. Iwaszko, Archiv. Metall. Mater. 57, 215 (2012).

[10] J. Iwaszko, Surf. Coat. Technol. 201, 3443 (2006).

[11] B. Veriansyah, J.-D. Kim, B. Koun Min, J. Kim, Mater. Lett. 64, 2197 (2010).

[12] D.R. Hummer, P.J. Heaney, J.E. Post, J. Cryst. Growth 344, 51 (2012).

[13] S. Gopinath, J. Philip, Mater. Chem. Phys. 145, 213 (2014).

[14] M. Gwoździk, Solid State Phenom. 203-204, 204 (2013).

[15] M. Gwoździk, Z. Nitkiewicz, Archiv. Metall. Mater. 58, 31 (2013).

[16] EN 10028-2:2009, Flat products made of steels for pressure purposes - Part 2: Non-alloy and alloy steels with specified elevated temperature properties. 